Revue bibliographique pour le domaine irano-aryen

Volume 37-38-39 | 2018

Comptes rendus des publications de 2014-2016

\title{
Michele Minardi. « New data on the Central Monument of Akchakhan-kala »
}

Johanna Lhuillier

\section{Q OpenEdition}

1 Journals

\section{Édition électronique}

URL : http://journals.openedition.org/abstractairanica/44689

DOI : 10.4000/abstractairanica.44689

ISBN : 1961-960X

ISSN : 1961-960X

Éditeur :

CNRS (UMR 7528 Mondes iraniens et indiens), Éditions de l'IFRI

Référence électronique

Johanna Lhuillier, « Michele Minardi. « New data on the Central Monument of Akchakhan-kala » », Abstracta Iranica [En ligne], Volume 37-38-39 | 2018, document 5, mis en ligne le 30 décembre 2018, consulté le 28 septembre 2020. URL : http://journals.openedition.org/abstractairanica/44689 ; DOI : https://doi.org/10.4000/abstractairanica.44689

Ce document a été généré automatiquement le 28 septembre 2020

Tous droits réservés 


\section{Michele Minardi. « New data on the Central Monument of Akchakhan- kala »}

Johanna Lhuillier

\section{RÉFÉRENCE}

Michele Minardi. « New data on the Central Monument of Akchakhan-kala », Bulletin of the Asia Institute 26/2012 [2016], p. 133-158.

1 Cet article, basé sur les travaux menés en 2015 par la mission karakalpako-australienne en Chorasmie Antique sur le Monument central d'Akchakhan-Kala, offre un complément à un précèdent paru dans la même revue (ce numero Minardi et Khozhaniyazov 2015). Il apporte des précisions sur la taille et l'architecture de l'édifice, notamment celle des pièces voûtées, accompagnées par des plans, des coupes stratigraphiques, des photographies et des reconstitutions volumétriques préliminaires.

2 Les travaux dans l'ensemble du site ont révélé qu'il s'agissait du siège d'une dynastie locale, où le zoroastrisme jouit un rôle clé, dans lequel le Monument central était probablement un complexe cérémoniel zoroastrien permettant également de célébrer la dynastie. L'auteur y voit un bâtiment collectif érigé par les rois chorasmiens pour y accueillir des cérémonies publiques en plein air, d'un type local, mais inspiré, selon l'auteur, ceux qu'on observe dans les complexes royaux achéménides. 


\section{AUTEURS}

JOHANNA LHUILLIER

UMR 5133 CNRS-Université de Lyon 